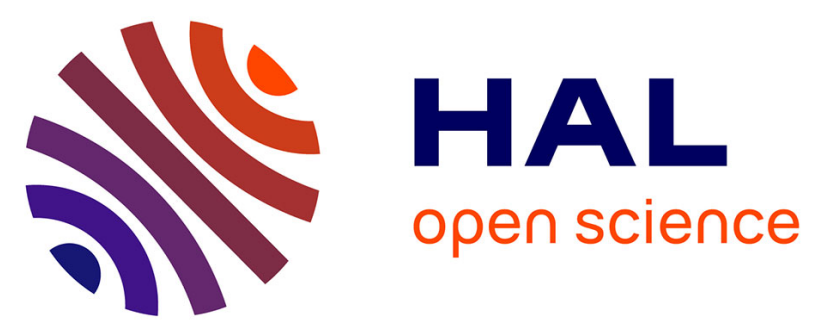

\title{
Silicon photonic on-chip spatial heterodyne Fourier transform spectrometer exploiting the Jacquinot's advantage
}

\author{
Thi Thuy Duong Dinh, David González-Andrade, Miguel
}

Montesinos-Ballester, Lucas Deniel, Bertrand Szelag, Xavier Le Roux, Eric

Cassan, Delphine Marris-Morini, Laurent Vivien, Pavel Cheben, et al.

\section{To cite this version:}

Thi Thuy Duong Dinh, David González-Andrade, Miguel Montesinos-Ballester, Lucas Deniel, Bertrand Szelag, et al.. Silicon photonic on-chip spatial heterodyne Fourier transform spectrometer exploiting the Jacquinot's advantage. Optics Letters, 2021, 46 (6), pp.1341. 10.1364/OL.418278 . hal-03320959

\section{HAL Id: hal-03320959 \\ https://hal.science/hal-03320959}

Submitted on 16 Aug 2021

HAL is a multi-disciplinary open access archive for the deposit and dissemination of scientific research documents, whether they are published or not. The documents may come from teaching and research institutions in France or abroad, or from public or private research centers.
L'archive ouverte pluridisciplinaire HAL, est destinée au dépôt et à la diffusion de documents scientifiques de niveau recherche, publiés ou non, émanant des établissements d'enseignement et de recherche français ou étrangers, des laboratoires publics ou privés. 


\title{
Silicon photonic on-chip spatial heterodyne Fourier transform spectrometer exploiting the Jacquinot's advantage
}

\author{
Thi Thuy Duong Dinh ${ }^{1}$,*, David González-Andrade ${ }^{2}$, Miguel Montesinos-Ballester $^{1}$, Lucas \\ Deniel ${ }^{1}$, Bertrand SzelaG ${ }^{3}$, Xavier Le Roux ${ }^{1}$, Eric Cassan $^{1}$, Delphine Marris-Morini ${ }^{1}$, \\ Laurent Vivien $^{1}$, Pavel Cheben ${ }^{4,5}$, Aitor V. Velasco ${ }^{2}$, and Carlos Alonso-Ramos ${ }^{1}$ \\ ${ }^{1}$ Centre de Nanosciences et de Nanotechnologies, CNRS, Université Paris-Sud, Université Paris-Saclay, Palaiseau 91120, France \\ ${ }^{2}$ Instituto de Óptica Daza de Valdés, Consejo Superior de Investigaciones Científicas (CSIC), Madrid 28006, Spain \\ ${ }^{3}$ University Grenoble Alpes and CEA, LETI, Minatec Campus, F-38054 Grenoble, Grenoble Cedex, France \\ ${ }^{4}$ National Research Council Canada, 1200 Montreal Road, Bldg. M50, Ottawa, Ontario K1A OR6, Canada \\ ${ }^{5}$ Center for Research in Photonics, University of Ottawa, Ottawa, Ontario K1N 6N5, Canada \\ *Corresponding author: thi-thuy-duong.dinh@c2n.upsaclay.fr
}

Compiled August 16, 2021

Silicon photonics on-chip spectrometers are finding important applications in medical diagnostics, pollution monitoring and astrophysics. Spatial heterodyne Fourier-transform spectrometers (SHFTS) provide a particularly interesting architecture with a powerful passive error correction capability and high spectral resolution. Despite having an intrinsically large optical throughput (étendue, also referred as Jaquinot's advantage), state-of-the-art silicon SHFTS have not exploited this advantage yet. Here, we propose and experimentally demonstrate for the first time an SHFTS implementing a wide-area light collection system simultaneously feeding an array of 16 interferometers, with an input aperture as large as $90 \mu \mathrm{m} \times 60 \mu \mathrm{m}$ formed by a twoway-fed grating coupler. We experimentally demonstrate $85 \mathrm{pm}$ spectral resolution, $600 \mathrm{pm}$ bandwidth and $13 \mathrm{~dB}$ étendue increase, compared with a device with a conventional grating coupler input. The SHFTS was fabricated using 193-nm deep-UV optical lithography and integrates the large-size input aperture with the interferometer array and monolithic Ge photodetectors, in a $4.5 \mathrm{~mm}^{2}$ footprint. (๑) 2021 Optical Society of America

\section{http://dx.doi.org/10.1364/ao.XX.XXXXXX}

Miniaturized on-chip silicon photonics spectrometers have been identified as an enabling tool for a wide range of applications, including medical diagnostics, biological and environmental monitoring, astrophysics and planetary science [0], to name a few. In integrated photonic spectrometers, light is collected and processed with a dispersive $[0,0,0,0,0,0]$ or a Fourier transform device $[0,0,0,0,0,0,0,0,0,0,0,0]$. Dispersive devices [0], e.g. arrayed waveguide gratings (AWGs) $[0,0]$ and waveguide echelle gratings $[0,0]$, have a single input waveguide, limit- ing the optical throughput, and therefore, compromising the signal-to-noise ratio. In addition, dispersive elements are quite sensitive to fabrication imperfections. Conversely, Fourier transform circuits enable multi-aperture inputs, where input area can be enlarged by increasing the number of apertures, benefiting from wider solid angles and thus an intrinsically large étendue, i.e., the Jacquinot's advantage [0]. A particularly promising architecture for miniaturized on-chip Fourier transform circuits is the spatial heterodyne Fourier transform spectrometer (SHFTS) $[0,0,0,0,0,0,0]$. SHFTS relies on an array of Mach-Zehnder interferometers (MZIs) with a linearly increasing optical path length imbalance, to form a spatial interferogram from which the input spectrum is retrieved [0]. SHFTS allows passive calibration techniques to correct amplitude and phase errors due to fabrication imperfections and achieve a high spectral resolution both in the near-IR $(40 \mathrm{pm})$ [0] and the mid-IR $(3 \mathrm{~nm})$ [0]. The parallel acquisition of the entire interferogram can be exploited to implement a multi-aperture light collection covering wide areas [0, 0]. However, silicon photonics on-chip SHFTSs reported to date have not yet exploited parallel acquisition with multi-aperture input, i.e. the Jacquinot's advantage. State-of-the-art SHFTS demonstrations use single-waveguide input and power splitting trees $[0,0,0]$ or multiple inputs that are accessed separately, one by one $[0,0]$. Reported SHFTSs rely on conventional fiber-chip grating couplers $[0,0]$ or facet couplers based on subwavelength engineered tapers $[0,0]$ of multimodal waveguides [0]. SHFTS have been monolithically integrated with one photodetector and one MZI [0].

Here, we propose and experimentally demonstrate a novel silicon on-chip SHFTS exploiting the Jacquinot's advantage, implementing on a wide-area collecting input formed by two grating couplers, side by side (see Fig.

In our SHFTS, a free-space propagating beam is collected and coupled into the chip using surface grating couplers. Due to the large difference between grating width and thickness, the design of transversal (along $y$ axis) and longitudinal (along $x$ 


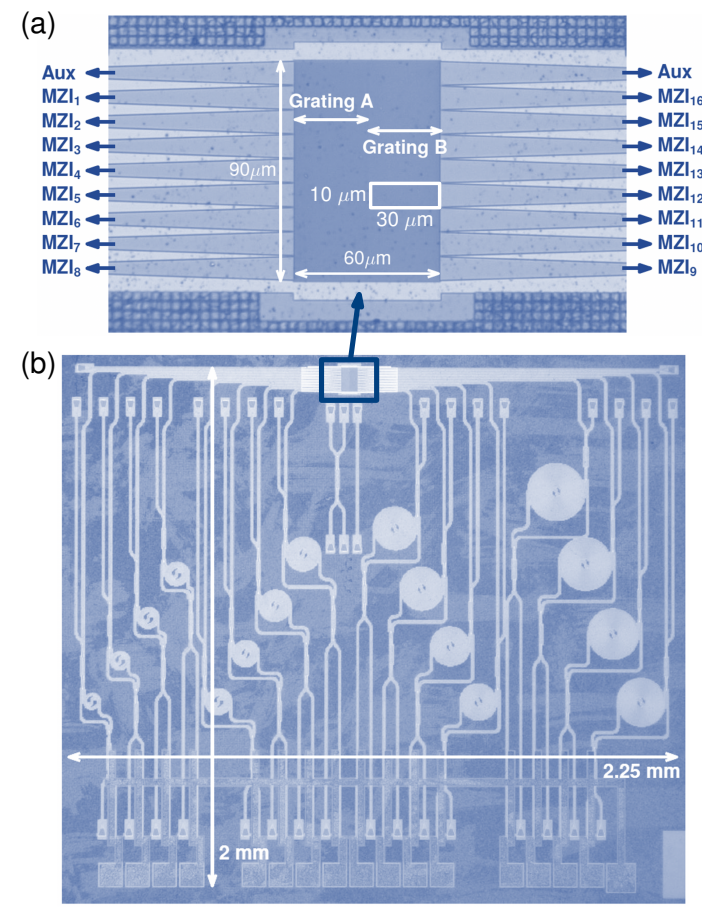

Fig. 1. Optical images of: (a) wide-area two-way-fed input grating coupler, and (b) complete SHFTS device, comprising the wide-area coupler, 16 MZIs and Ge photodetectors.

axis) geometries can be treated separately [0]. On the one hand, grating couplers can be made arbitrarily wide. Thus, they can be readily designed to match any desired input beam width. On the other hand, the maximum effective grating length that can be implemented is limited by grating radiation strength. The effective grating length can be increased, weakening the radiation strength by reducing the grating contrast, e.g. using subwavelength index engineering [0]. Nevertheless, the minimum achievable strength may be limited by fabrication constraints like minimum feature size or sensitivity to imperfections. Here, we propose an alternative approach to increase the grating length, based on connecting two grating couplers with opposite radiation angles. This approach allows doubling the total length of the light collecting region without the need to halve the grating strength, while facilitating excitation of multiple waveguides as light is coupled towards the two sides of the grating.

Let us consider the 2D grating geometry shown in Fig.

To illustrate the advantage of this two-way-fed configuration, we calculate the coupling efficiency as a function of the grating length, $L=L_{A}+L_{B}$, when a plane wave truncated to $100 \mu \mathrm{m}$ width is used as input. The plane-wave propagation angle $\theta$, defined in Fig.

The proposed SHFTS comprises 16 MZIs with a maximum path-length imbalance of $7.5 \mathrm{~mm}$, resulting in a theoretical resolution of $75 \mathrm{pm}$ [0]. The SHFTS was fabricated at CEA Leti with 193-nm deep-UV optical lithography. The silicon guiding layer is $300 \mathrm{~nm}$ thick and the buried oxide layer (BOX) has a thickness of $720 \mathrm{~nm}$. A two-step etch process was used to define shallowand full-etch trenches of the grating couplers and the interconnecting strip waveguides. The integrated photodetectors were fabricated using Ge epitaxial growth, boron, phosphorus ion implantation, and standard CMOS metallization steps. Figure

Interconnection waveguides are $450 \mathrm{~nm}$ wide, ensuring

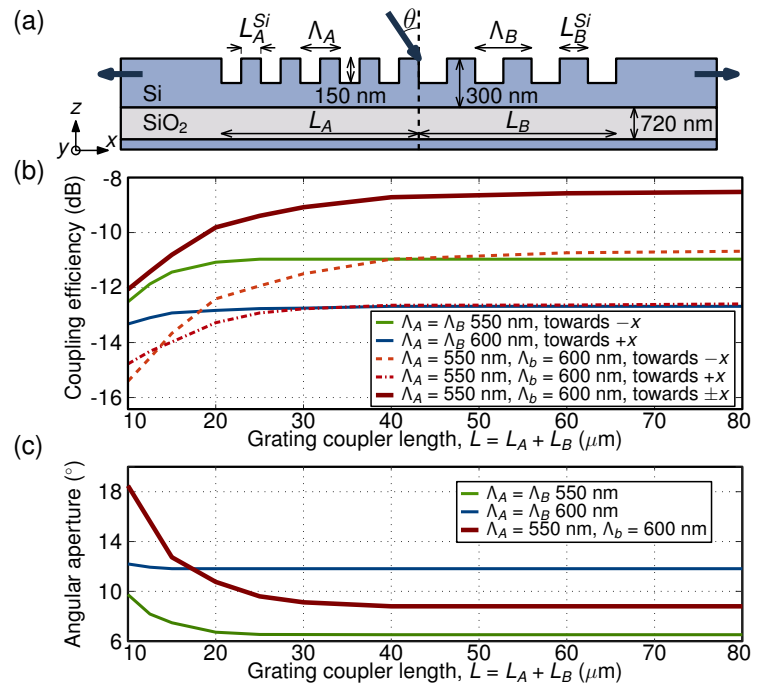

Fig. 2. (a) Schematic 2D view of the two-way-fed grating coupler. (b) Coupling efficiency as a function of the grating length, when a plane wave of $100 \mu \mathrm{m}$ length is used as the input. (c) Angular aperture as a function of the grating length.

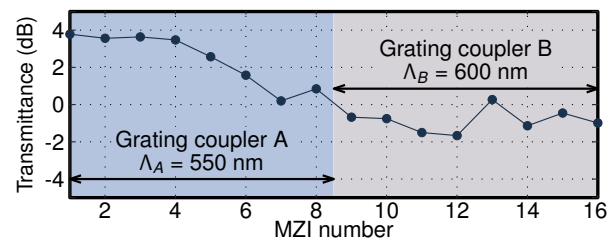

Fig. 3. Transmittance of the 16 MZIs in the SHFTS near $1570 \mathrm{~nm}$ wavelength, when simultaneously illuminated with a GRIN lens collimator and the two-way-fed grating. 
single-mode operation. Length imbalance in the MZIs is implemented using spirals with bending radius ranging from 10 $\mu \mathrm{m}$ to $100 \mu \mathrm{m}$. The MZIs are implemented with $2 \times 2$ multi-mode interference couplers. One input of each MZI is connected to the wide-area two-way-fed grating coupler, and one MZI output is connected to an integrated germanium photodetector, with the responsivity of $0.6 \mathrm{~A} / \mathrm{W}$. The other two ports of the MZI are connected to conventional fibre-chip grating couplers, for reference. Conventional fiber-chip grating couplers have a period of $600 \mathrm{~nm}$, a duty cycle of 0.5 and size of $\sim 20 \times 20 \mu \mathrm{m}^{2}$. The MZIs in the SHFTS can be excited simultaneously using the twoway-fed grating, or one by one using conventional fiber-chip couplers. The output of each MZI is readout either using integrated photodetectors, or with SMF-28 fibers and analyzed using external photodetectors. To illuminate the wide-area grating, we use a fiber gradient-index (GRIN) lens collimator with a beam diameter of $0.5 \mathrm{~mm}$, at full-width at half maximum (FWHM).

As shown in Fig.

First, we characterize the étendue improvement of the twoway-fed grating. The étendue is the product of the input area, the coupling efficiency and the solid angle [0]. For comparison, we use a conventional grating coupler, with a size of $20 \times 20 \mu \mathrm{m}^{2}$, similar to the size of the individual inputs of our coupler, of 10 $\times 30 \mu \mathrm{m}^{2}$ each. Having comparable areas, they will have similar angular apertures, allowing direct comparison of the étendue using the peak coupling efficiency. We illuminate the widearea grating with the GRIN collimator and collect the output of the 16 MZIs, using an SMF-28 fiber and the ports connected to conventional fiber-chip grating couplers. The signal collected at each output port is normalized by the transmittance of two conventional grating couplers in a back-to-back configuration when using the GRIN collimator at the input and SMF-28 fiber at the output. The transmittance of the 16 MZIs near $1570 \mathrm{~nm}$ wavelength is shown in Fig.

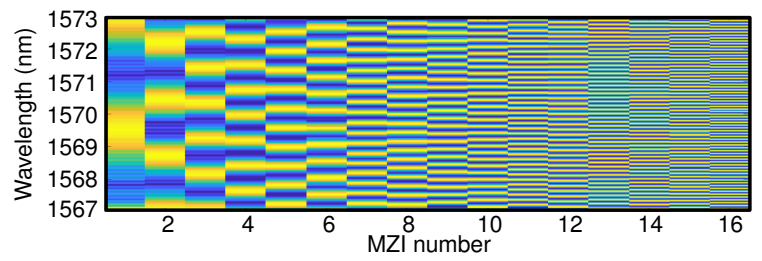

Fig. 4. Calibration matrix measured for the $16 \mathrm{MZIs}$ and the input aperture illuminated using GRIN lens collimator, and output with integrated Ge photodetectors.

To calibrate the SHFTS and retrieve the input spectrum from the spatial interferogram, $I$, formed at the outputs of the MZI array, we use the pseudoinverse transfer matrix method [0]. The interferogram can be expressed as $I=B \times T$, where $B$ is the spectrum at the input and $T$ is a transformation matrix containing the measured transmittance data for each MZI. The input spectrum is retrieved by multiplying the interferogram by the pseudoinverse of the transformation matrix $T$. This retrieval method allows passive correction of amplitude and phase errors arising from fabrication imperfections [0].

We have compared the spectral retrieval of the SHFTS using four possible configurations combining the two inputs (widearea two-way-fed and conventional grating) and the two outputs (integrated Ge photodetector and conventional fiber-chip coupler) of the MZIs. In each case, a different calibration matrix is recorded and used for spectral retrieval. As an example, Fig.
To optimize the signal-to-noise ratio of the retrieved spectrum, we truncate the callibration matrix to $600 \mathrm{pm}$ wavelength range. Figure
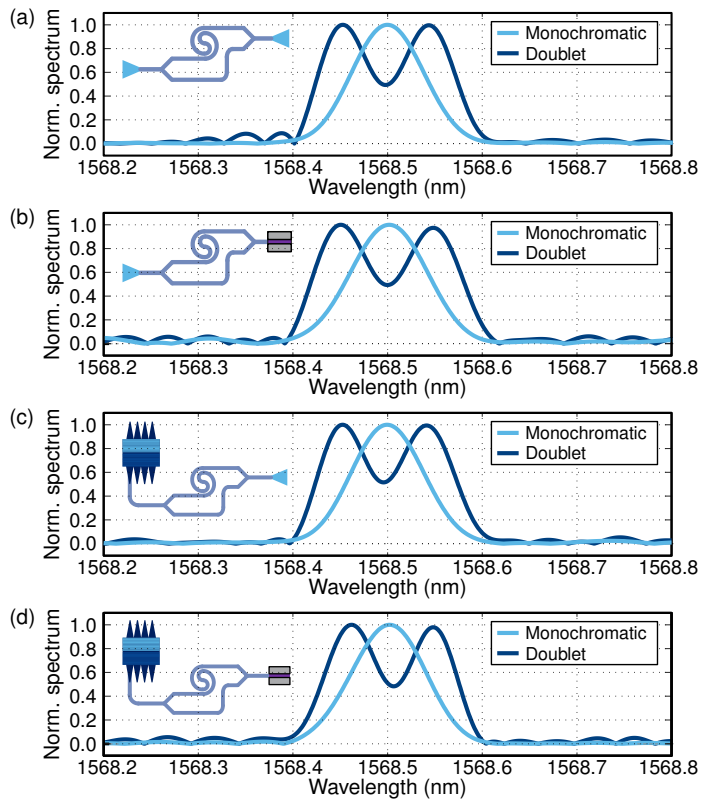

Fig. 5. Retrieved spectrum of a monochromatic input and a doublet with peak-to-peak separation of 85 pm, for: (a) illumination with conventional grating coupler, readout with external photodetector, (b) illumination with conventional grating coupler, readout with integrated Ge photodetectors, (c) illumination with two-way-fed grating, readout with external photodetector, and (d) illumination with two-way-fed grating, readout with integrated Ge photodetectors.

In summary, we report on the experimental demonstration of the SHFTS fabricated using 193-nm deep-UV optical lithography, comprising a wide-area light collecting aperture of 90 $\mu \mathrm{m} \times 60 \mu \mathrm{m}$ and integrated Ge photodetector array. The device relies on a novel two-way-fed grating geometry, combining two grating couplers with opposite radiation angle to simultaneously feed 16 Mach-Zehnder interferometers. We experimentally show a $\sim 13 \mathrm{~dB}$ increase in étendue, compared with a conventional input grating coupler aperture, when using a wide-area illumination beam of $0.5 \mathrm{~mm}$ FWHM. We compared different device configurations, illuminating all MZI simultaneously with wide-area collection input or one by one with conventional fiberchip couplers, and recording the MZI outputs with integrated Ge photodetectors and external photodetectors. The large étendue of the proposed configuration and the powerful phase and amplitude corrections provided by the pseudoinverse technique allowed the demonstration of $85 \mathrm{pm}$ resolution using wide-area input aperture and integrated photodetectors, with no significant performance degradation compared to individual illumination of each MZI and readout with external photodetectors. These results open a new route to large-volume production of miniaturized silicon photonic on-chip spectrometers exploiting the Jaquinot's advantage, which can be particularly interesting for sensing applications in embarked systems where weight, robustness, and étendue are key parameters [0]. 


\section{FUNDING}

French Industry Ministry (Nano2022 project under IPCEI program); Agence Nationale de la Recherche (ANR-MIRSPEC-17CE09-0041); Spanish Ministry of Science, Innovation and Universities (MICINN) (RTI2018-097957-B-C33, TEC2015-71127-C21-R FPI scholarship BES-2016-077798); Community of Madrid FEDER funds (S2018/NMT-4326); Horizon 2020 Research and Innovation Program (Marie Sklodowska-Curie 734331);

\section{DISCLOSURES}

The authors declare no conflicts of interest.

\section{REFERENCES}

1. M. Ferrari, and V. Quaresima, Neuroimage, 63, 921 (2012).

2. P. Cheben, Optical Waveguides: from Theory to Applied Technologies, (CRC Press, London, 2007), Chap. 5.

3. B. I. Akca and C. R. Doerr, IEEE Photonics Technol. Lett., 31, 90 (2019).

4. P. Cheben, J.H. Schmid, A. Delâge, A. Densmore, S. Janz, B. Lamontagne, J. Lapointe, E. Post, P. Waldron, and D.-X. Xu, Opt. Express, 15, 2299 (2007).

5. S. Janz, A. Balakrishnan, S. Charbonneau, P. Cheben, M. Cloutier, A. Delâge, K. Dossou, L. Erickson, M. Gao, P.A. Krug, B. Lamontagne, M. Packirisamy, M. Pearson, and D.-X Xu, IEEE Photon. Technol. Lett., 16, 503 (2004).

6. K. Ma, K. Chen, N. Zhu, L. Liu, and S. He, IEEE Photonics J., 11, 4900107 (2018).

7. S. Zheng, H. Cai, J. Song, J. Zou, P. Y. Liu, Z. Lin, D.-L. Kwong, and A.-Q. Liu, IEEE Photonics J., 11, 6602809 (2019).

8. P. Cheben, I. Powell, S. Janz, D.-X. Xu, Opt. Lett. 30, 1824 (2005).

9. M. Florjańczyk, P. Cheben, S. Janz, A. Scott, B. Solheim, and D. X. Xu, Opt. Express 15, 18176 (2007).

10. A. V. Velasco, P. Cheben, P. J. Bock, A. Delâge, J. H. Schmid, J. Lapointe, S. Janz, M. L. Calvo, D.-X. Xu, M. Florjanczyk, and M. Vachon, Opt. Lett., 38, 706 (2013).

11. P. J. Bock, P. Cheben, A. V. Velasco, J. H. Schmid, A. Delâge1, M. Florjańczyk, J. Lapointe, D.-X. Xu, M. Vachon, S. Janz, and M. L. Calvo, Laser Photonics Rev., 7, L67 (2013).

12. M. Nedeljkovic, A. V. Velasco, A. Z. Khokhar, A. Delâge, P. Cheben, and G. Z. Mashanovich, IEEE Photonics Technol. Lett., 28, 528 (2016).

13. H. Podemore, A. Scott, P. Cheben, A. V. Velasco, J. H. Schmid, M. Vachon, and R. Lee, Opt. Lett., 42, 1440 (2017).

14. Q. Liu, J. M. Ramirez, V. Vakarin, X. Le Roux, C. Alonso-Ramos, J. Frigerio, A. Ballabio, E. Talamas Simola, D. Bouville, L. Vivien, G. Isella, and D. Marris-Morini, Opt. Lett., 43, 5021 (2018).

15. H. Wang, Q. Li, and W. Shi, Opt. Lett., 45, 1479 (2020).

16. X. Nie, E. Ryckeboer, G. Roelkens, and R. Baets, Opt. Express, 25, A409 (2017).

17. R. A. Soref, F. De Leonardis, and V. M. N. Passaro, J. Lightwave Technol., 37, 3192 (2019).

18. M. C. M. M. Souza, A. Grieco, N. C. Frateschi, and Y. Fainman, Nat. Commun., 9, 665 (2018).

19. D. M. Kita, B. Miranda, D. Favela, D. Bono, J. Michon, H. Lin, T. Gu, and J. Hu, Nat. Commun., 9, 4405 (2020).

20. P. Jacquinot, J. Opt. Soc. Am. 44, 761 (1954).

21. M. Florjańczyk, C. Alonso-Ramos, P. J. Bock, A. Bogdanov, P. Cheben, I. Molina-Fernández, S. Janz, B. Lamontagne, A. Ortega-Moñux, A. Scott, K. Sinclair, B. Solheim, and D.-X. Xu, Opt. and Quant. Electron. 44, 549 (2012).

22. Y. Li, M. Vanslembrouck, and R. Baets, in Advanced Photonics (OSA, 2016), paper ITu1B.5.

23. D. Taillaert, P. Bienstman, and R. Baets, Opt. Lett. 29, 2749 (2004).

24. R. Halir, P. Cheben, S. Janz, D.-X. Xu, I. Molina-Fernández, and J. G. Wangüemert-Pérez, Opt. Lett. 34, 1408 (2009).

25. D. M. Sonnenfroh, and M. G. Allen, Appl. Opt. 36, 3298 (1997).

26. J. A. Shaw, Am. J. Phys. 81, 33-37 (2013).

\section{REFERENCES}

1. M. Ferrari, and V. Quaresima, "A brief review on the history of human functional near-infrared spectroscopy (fNIRS) development and fields of application," Neuroimage., 63(2), 921-935 (2012).

2. P. Cheben, "Wavelength dispersive planar waveguide devices: echelle gratings and arrayed waveguide gratings," in Optical Waveguides: from Theory to Applied Technologies, M. L. Calvo and V. Lakshminarayanan, eds. (CRC Press, London, 2007), Chap. 5.

3. B. I. Akca and C. R. Doerr, "Interleaved silicon nitride AWG Spectrometers," IEEE Photonics Technol. Lett., 31(1), 90-93 (2019).

4. P. Cheben, J.H. Schmid, A. Delâge, A. Densmore, S. Janz, B. Lamontagne, J. Lapointe, E. Post, P. Waldron, and D.-X. Xu, "A high-resolution silicon-on-insulator arrayed waveguide grating microspectrometer with sub-micrometer aperture waveguides," Opt. Express, 15(5), 2299-2306 (2007).

5. S. Janz, A. Balakrishnan, S. Charbonneau, P. Cheben, M. Cloutier, A. Delâge, K. Dossou, L. Erickson, M. Gao, P.A. Krug, B. Lamontagne, M. Packirisamy, M. Pearson, and D.-X Xu, "Planar waveguide echelle gratings in silica-on-silicon," IEEE Photon. Technol. Lett., 16(2), 503505 (2004).

6. K. Ma, K. Chen, N. Zhu, L. Liu, and S. He, "High-resolution compact on-chip spectrometer based on an Echelle grating with densely packed waveguide array," IEEE Photonics J., 11(1), 4900107 (2018).

7. S. Zheng, H. Cai, J. Song, J. Zou, P. Y. Liu, Z. Lin, D.-L. Kwong, and A.-Q. Liu, "A single-chip integrated spectrometer via tunable microring resonator array," IEEE Photonics J., 11(5), 6602809-6602809 (2019).

8. P. Cheben, I. Powell, S. Janz, D.-X. Xu, "A new wavelength dispersive device based on a Fourier transform Michelson type arrayed waveguide grating," Opt. Lett. 30(14), 1824-1826 (2005).

9. M. Florjańczyk, P. Cheben, S. Janz, A. Scott, B. Solheim, and D. X. $\mathrm{Xu}$, "Multiaperture planar waveguide spectrometer formed by arrayed Mach-Zehnder interferometers," Opt. Express 15(26), 18176-18189 (2007).

10. A. V. Velasco, P. Cheben, P. J. Bock, A. Delâge, J. H. Schmid, J. Lapointe, S. Janz, M. L. Calvo, D.-X. Xu, M. Florjanczyk, and M. Vachon, "High-resolution Fourier-transform spectrometer chip with microphotonic silicon spiral waveguides," Opt. Lett., 38(5), 706-709 (2013).

11. P. J. Bock, P. Cheben, A. V. Velasco, J. H. Schmid, A. Delâge1, M. Florjańczyk, J. Lapointe, D.-X. Xu, M. Vachon, S. Janz, and M. L. Calvo, "Subwavelength grating Fourier-transform interferometer array in silicon-on-insulator," Laser Photonics Rev., 7(6), L67-L70 (2013).

12. M. Nedeljkovic, A. V. Velasco, A. Z. Khokhar, A. Delâge, P. Cheben, and G. Z. Mashanovich, "Mid-infrared silicon-on-insulator Fourier transform spectrometer chip," IEEE Photonics Technol. Lett., 28(4), 528-531 (2016).

13. H. Podemore, A. Scott, P. Cheben, A. V. Velasco, J. H. Schmid, M. Vachon, and R. Lee, "Demonstration of a compressive-sensing Fouriertransform on-chip spectrometer," Opt. Lett., 42(7), 1440-1443 (2017).

14. Q. Liu, J. M. Ramirez, V. Vakarin, X. Le Roux, C. Alonso-Ramos, J. Frigerio, A. Ballabio, E. Talamas Simola, D. Bouville, L. Vivien, G. Isella, and D. Marris-Morini, "Integrated broadband dual-polarization Ge-rich SiGe mid-infrared Fourier-Transform spectrometer," Opt. Lett., 43(22), 5021-5024 (2018).

15. H. Wang, Q. Li, and W. Shi, "On-chip polarization-insensitive Fourier transform spectrometer," Opt. Lett., 45(6), 1479-1482 (2020).

16. X. Nie, E. Ryckeboer, G. Roelkens, and R. Baets, "CMOS-compatible broadband co-propagative stationary Fourier transform spectrometer integrated on a silicon nitride photonics platform," Opt. Express, 25(8), A409-A418 (2017).

17. R. A. Soref, F. De Leonardis, and V. M. N. Passaro, "Scanning spectrometer-on-a-chip using thermo-optical spike-filters or Verniercomb filters," J. Lightwave Technol., 37(13), 3192-3200 (2019).

18. M. C. M. M. Souza, A. Grieco, N. C. Frateschi, and Y. Fainman, "Fourier transform spectrometer on silicon with thermo-optic non-linearity and dispersion correction," Nat. Commun., 9, 665 (2018).

19. D. M. Kita, B. Miranda, D. Favela, D. Bono, J. Michon, H. Lin, T. Gu, and J. Hu, "High-performance and scalable on-chip digital Fourier transform spectroscopy," Nat. Commun., 9, 4405 (2020). 
20. P. Jacquinot, "The luminosity of spectrometers with prisms, gratings, or Fabry-Perot etalons," J. Opt. Soc. Am. 44(10), 761-765 (1954).

21. M. Florjańczyk, C. Alonso-Ramos, P. J. Bock, A. Bogdanov, P. Cheben, I. Molina-Fernández, S. Janz, B. Lamontagne, A. Ortega-Moñux, A. Scott, K. Sinclair, B. Solheim, and D.-X. Xu, "Development of a Fouriertransform waveguide spectrometer for space applications," Opt. and Quant. Electron. 44(12), 549-556 (2012).

22. Y. Li, M. Vanslembrouck, and R. Baets, "Two-way-fed silicon-oninsulator grating couplers with a broad bandwidth," in Advanced Photonics (OSA, 2016), paper ITu1B.5.

23. D. Taillaert, P. Bienstman, and R. Baets, "Compact efficient broadband grating coupler for silicon-on-insulator waveguides," Opt. Lett. 29(23), 2749-2751 (2004).

24. R. Halir, P. Cheben, S. Janz, D.-X. Xu, I. Molina-Fernández, and J. G. Wangüemert-Pérez, "Waveguide grating coupler with subwavelength microstructures," Opt. Lett. 34(9), 1408-1410 (2009).

25. D. M. Sonnenfroh, and M. G. Allen, "Observation of $\mathrm{CO}$ and $\mathrm{CO}_{2}$ absorption near $1.57 \mu \mathrm{m}$ with an external-cavity diode laser," Appl. Opt. 36(15), 3298-3300 (1997).

26. J. A. Shaw, "Radiometry and the Friis transmission equation," Am. J. Phys. 81, 33-37 (2013). 